\title{
Closed Product Life Cycle as a Basis of the Circular Economy
}

\author{
Maria Vetrova $^{1}$, Dinara Ivanova ${ }^{2}$ \\ ${ }^{1,2}$ St.Petersburg State University, 7-9 Universitetskaya Emb., 199034, Saint-Petersburg, Russia
}

\begin{abstract}
Objective - The circular economy aims to preserve the value of products and materials within a closed supply chain. The existing models and decision-making methods for managing the end of the product life cycle are mostly focused on the economic aspects. While the circular economy is aimed at combining environmental, economic and social goals. This article aims to develop a model for enterprise decision-making on the disposal of used products, taking into account socio-environmental and economic factors.

Methodology/Technique - The article analyzes the impact of digital technologies on the formation of closed supply chains and the development of a circular economy. At the same time, special attention is focused on the model of a closed product life cycle, as a fundamental element in the formation of a circular economy at the micro and nano levels, as well as the importance of using digital technologies at all stages of the product life cycle.

Findings - The methods of product management at the end of the life cycle studied in the article have made it possible to form a simulation decision support model regarding the method of product disposal, taking into account environmental and economic feasibility.
\end{abstract}

Novelty - This study identified the main trends in the development of closed supply chains under the influence of digital technologies in the context of a circular economy.

Type of Paper: Review

JEL Classification: F42, F43

Keywords: Circular Economy; Digital Technology; Decision-making Model; Closed-loop Supply Chains

Reference to this paper should be made as follows: Vetrova, M; Ivanova, D. (2021). Closed Product Life Cycle as a Basis of the Circular Economy, J. Bus. Econ. Review, 5(4) 36-50. https://doi.org/10.35609/jber.2021.5.4(4)

\section{Introduction}

One of the key goals of sustainable development is ensuring sustainable production and consumption patterns. To achieve this goal, it is necessary to transform the linear economy, based on the principle of "take, make, waste", into a circular economy, where the value of all products and materials remains in a closed supply chain. The global trend of digitalization has led to the possibility of efficient formation of closed supply chains and today more and more attention is being drawn to the concept of a circular economy, which has a restorative nature based on the principle of "take, make, reuse" (Pakhomova, Richter, Vetrova, 2017).

\footnotetext{
* Paper Info: Revised: December 21, 2020

Accepted: March 31, 2021

* Corresponding author: Maria Vetrova

E-mail: m.a.vetrova@spbu.ru

Affiliation: Faculty of Economics, Saint Petersburg State University, Russia.
}

Companies around the world are actively implementing the principles of the circular economy at all stages of value creation, striving to develop closed supply chains. For example, Apple uses a special robot to extract 
iPhone components and materials that can be reused or recycled, to date, 61 million pounds of materials have already been extracted, including 2,204 pounds of gold worth \$ 40 million. (Whitwam, 2016). John Deer Company (2019) is engaged in the restoration of spare parts and motors for outsizal equipment, which saves up to $70 \%$ of the cost of the product, and over the past 5 years the company has reduced the amount of waste by 56.7 ths. tons.

Governments of various states and public organizations also take measures to promote the development of a circular economy. For example, EU countries are developing roadmaps and special programs such as Finland's National Circular Economy Roadmap, ProgRess II-German Resource Efficiency Program, Leading the transition: a circular economy action plan for Portugal, Towards a Model of Circular Economy for Italy - Overview and Strategic Framework, France Unveils Circular Economy Roadmap, Roadmap towards the Circular Economy in Slovenia and others.

The most active non-governmental organization The Ellen MacArthur Foundation is engaged in research and informing society about the positive effects of the dissemination of the principles of the circular economy, combining the goals of the state and business in the field of sustainable development. The fund works at a strategic level with leading companies in key sectors of the economy to demonstrate circular innovations on a global scale and their potential as a new source of value creation.

Based on digital technologies, circular business models are being introduced into production and consumption processes to simultaneously achieve social, economic and environmental efficiency. Digital technologies have fundamentally changed consumer behavior, company performance and the interconnectedness of all elements of the economy. So, the mobile Internet provides an opportunity for the hyper-connection of subjects and objects of the digital economy. Artificial intelligence provides algorithmic decision-making and automatic process control. BigData technologies make it possible to process a huge amount of structured and unstructured data and create predictive analytics. Cloud computing enables the transfer of complex data and knowledge to various ecosystem participants. Robots of new generation have virtually eliminated human involvement in many processes. Augmented reality makes it possible to see objects and business processes in a holistic and detailed way. The Internet of things allows control over processes and systems remotely, and the blockchain provides verification of participants and the reliability of the transaction.

All these technologies made it possible to embark on the path to the implementation of the Digital circular economy, which is characterized by non-waste production and consumption, minimal material costs per unit of production and the conversion of commercial and personal waste into a useful resource for further use.

The digital circular economy, aimed at the entire product life cycle from production and consumption to waste landfill and the market of secondary raw materials, involves a number of measures to "close the loop" of the product life cycle due to increased recycling and reuse of products. The development of digital circular economy is associated with positive effects, such as saving resources up to $98 \%$, energy up to $68-83 \%$, reducing carbon dioxide emissions up to $73-87 \%$, as well as reducing the cost of the finished product up to $30-40 \%$ (Yang et. al., 2015). The development of the digital circular economy begins with the micro level of a separate enterprise, where the company decides to implement the principles of the circular economy and is responsible for the disposal of products at the end of its use in one of the most effective ways: reuse, repair, restoration, recycling.

Moreover, each of the methods has a different degree of environmental efficiency, the most unfavorable of which are the burning and burial of products at the landfill, they do not apply to circular principles and business models, because not aimed at saving resources and reducing greenhouse gas emissions. At the same time, the least environmentally friendly methods in the linear model of production and consumption are optimal in terms of costs. Among other things, the transition to a closed supply chain requires significant investment with a long payback period. Therefore, when deciding on the implementation of circular business models, companies make a choice between adopting the practices of different disposal methods. 
Many studies in the field of waste management confirm the urgency of the problem of choosing between an economically feasible and environmentally efficient method of disposal. A systematic review of the literature conducted by Tsai F., Bui T. et all. (2020) identified 413 studies in waste management in the context of the circular economy. Analysis of waste management models by Morrisseya and Browne (2008) confirms that all models are based on cost-benefit analysis, product lifecycle assessment, decision-making aimed at the decision stage, not the process. It is also possible to distinguish models related to risk assessment and benchmarking. Allesch and Brunner (2014) estimate that approximately $40 \%$ of existing studies focus on life cycle assessment, $50 \%$ determine the best waste management options, and economic aspects are considered in approximately $50 \%$ of the studies. However, existing models, while recognizing the importance of sustainable development, do not take into account all aspects related to environmental, economic and social effects.

Thus, the aim of the study is, firstly, to analyze the possibilities of using digital technologies to implement a closed model of the product life cycle; secondly, the development of an enterprise decision-making model for the disposal of used products taking into account socio-environmental and economic factors; and thirdly, the identification of the main trends in the development of supply chains and their transformation into whole ecosystems, coordinating actions of all participants and elements of the chain.

The research consists of 6 sections:

1. The introduction substantiates the relevance of the research, sets objectives, provides the structure of the research.

2. The literature review presents an analysis of research in the field of circular economy, digital transformation, as well as models and methods for managing return flows of products at the end of use, taking into account environmental and economic efficiency.

3. Research Methodology presents theoretical and methodological approaches to research, the specifics of creation a decision support model and data sources.

4. The Results present a model of a closed product life cycle, supported by digital technologies, the model for making decisions on the method of product disposal at the end of its life cycle, as well as the main trends in the development of closed supply chains.

5. Discussion presents the possibilities of using the developed tools and promising areas of research in the presented topic.

6. Conclusion.

\section{Literature Review}

The number of scientific papers and best practices in the application of circular business models has been steadily increasing in recent years. If in 2016 the number of publications related to the circular economy amounted to about 400, in 2018 the number of studies grew to 1000 (Ngan, How, Teng et. al., 2019).

All studies are of a multidirectional nature, some authors study the theoretical aspects of the circular economy, others focus on the practical effects during its development both at the level of individual companies and at the level of regions and countries. The basic elements of the circular economy have been studied through environmentally conscious production and product reuse. At the end of the 1990s, a number of leading experts with an international reputation, including Gupta (1999), drew attention to high importance of these basic elements, which they reconciled with the formation of the following four interconnected links that have retained their relevance to this day: environmental product design, reverse logistics, closed-loop supply chains and remanufacturing, which are integral parts of the theoretical and practical development of the circular economy.

Kirchherr, Reike, Hekkert (2017) studied 114 definitions of circular economy and, having analyzed various aspects of the concept, derived the actual definition. By circular economy they mean an economic 
system that replaces the 'end-of-life' concept with reducing, alternatively reusing, recycling and recovering materials in production/distribution and consumption processes. The significant positive effects of the circular economy have been analyzed in the works of many authors. For example, Yang (2015) has proven resource and energy savings in the production of finished products, reduction of $\mathrm{CO} 2$ emissions, as well as significant economic effects as lower product costs. Of particular interest are studies of business models in a circular economy. Lewandoski (2016) presented 25 business models of a circular economy, which are related to such operations for closing the chain as reuse, restoration, exchange, etc.

There is the difficulty of return flow management and decision-making on the choice of disposal method, taking into account economic and environmental efficiency. Ghisellini, Cialani (2016), Milutinović, Stefanović (2017), Ruiz-Peñalver, Rodríguez (2019) used life cycle assessment to develop waste management models to minimize negative environmental impacts. Zaccariello, Cremiato (2015), Cremiato, Mastellone (2017), Ferronato, Rada (2019) used feasibility studies to identify optimal approaches to end-ofuse product and waste management.

At the same time, not all companies are actively developing circular business models and introducing the principles of circular economy into their practice, since this requires high investment costs with a long payback period; there is the difficulty of return flow management and decision-making on the choice of disposal method, taking into account economic and environmental efficiency. However, Antikainen and Uusitalo (2018) and Kristoffersen and Blomsma (2020) argue that digital technologies can help achieve high economic efficiency while reducing environmental impact and accelerate the transition to a circular economy.

In the past few years, digital transformation has been carried out, which represents the transition of society to an increasingly digital form of operations with a fundamental change in the main source of added value and the structure of the economy through the formation of more efficient commercial and production processes, supported by digital technologies. These technologies include artificial intelligence, the Internet of Things, unmanned vehicles, blockchain, big data analytics, 3D printing, nanotechnology, biotechnology, quantum computers. The first terms, as well as the concept of the modern digital economy, appeared in 1995, when the American computer scientist Negroponte (1995) used a metaphor about the transition from the processing of atoms that make up the matter of physical substances to the processing of bits that make up the matter of program codes. Negroponte N. said that material substances in the form of raw materials and products have their disadvantages such as: the physical weight of the product, the need for resources for its production, the use of storage space, logistics costs and problems related to the transportation of products. The advantages of the digital economy as a "new" type of economy, in the opinion of a computer scientist, could be: the absence of the physical weight of products replaced by the information volume, lower resource use for the production of electronic goods, several times smaller area occupied by products (usually electronic media), as well as instant global movement of goods via the Internet. Development opportunities, positive and negative effects of the digital economy, tools and mechanisms for its implementation in the last decade have been actively studied by scientists around the world.

The term "Industry 4.0" was introduced during drawing up the development program of the German economy in 2011 (Plattform Industrie 4.0), therefore, this term is most often used in German-language literature (Kagermann, Lukas \& Wahlster, 2011). In the English-language literature, a similar idea and policy to support scientific research in the United States is formulated called the Industrial Internet Consortium (2013), which is based on the idea of the Internet of Things, formulated by Kevin Ashton in 1999. The Internet of Things is the idea of connecting household items to the Internet, thanks to which they can interact with the external environment and with each other, collect the necessary data and, on their basis, autonomously (without human participation) take actions and perform operations.

The analysis of scientific research shows that in recent years there have been works on the impact of the Internet of Things on the development of healthcare, urban infrastructure, certain functional areas of the 
organization, as well as tools for forming business models for the commercialization of IoT products and applications (Dijkman, Sprenkels, Peeters, \& Janssen, 2015). There are also studies on the social consequences of digital transformation for the development of society and the environmental consequences of the increasing spread of digital technologies (Frey \& Osborne, 2016; Wolfram \& Gampl, 2008). The influence of digital technologies on the development of a circular economy is highlighted in the studies of Arenkov and Tsenzharik (2019) and Pakhomova and Rikhter, (2017). At the same time to form a circular economy, it is significant to use digital technologies starting from the nano-level of development and environmental design of a product, to the micro-level of organizing optimal processes of production, consumption and management of products at the end of life cycle in the most efficient way in terms of economic, environmental and social impacts.

Analysis of research in the field of economic and mathematical methods and models for waste management at the end of the product life cycle showed a wide range of scientific papers that are devoted to various aspects of theory and practice. Jawahir and Bradley (2016) show that existing end-of-life product management models can be divided into Remanufacture, Repair, Recondition, Cannibalization, Redesign, Refurbish and Recycle. Kumar and Shirodkar (2007) argue that different factors must be considered when choosing how to manage a product at the end of the life cycle. According to Stewart and Ijomah (2011), decision-making models for choosing a disposal method rely on economic and technical data. However, Alamirew and Brissaud (2019) argue for the need to apply a holistic approach to the choice of how to manage end of the life cycle products, including economic, environmental and social effects.

For example, Karimi, Mahmoudzadeh and Mansour (2013) using integer linear programming designed the return supply chain for the disposal of used vehicles. Bribian, Ferreira, Aranda Usón and Vasquez (2012) used scenario modeling to quantify the environmental performance of a used tire management system in terms of carbon dioxide emissions. Simić and Dimitrijević (2012) using linear programming, evaluated the profitability of recycling enterprises, the achievability of standard utilization and recycling ratios in the EU. Krishna Mohan and Amit (2020) using a dynamic model try to solve the dismantling dilemma and answer the question of how to reduce the costs of dismantling at the end of the product life cycle. However, the considered models do not take into account the product management costs at the end of its life cycle and the rate of environmental fees in case of refusal of its disposal.

From this angle, using linear programming the article "Strategic response to EEE returns: Product ecodesign or new recovery processes?" (Zuidwijk \& Krikke (2007) shows the research on strategic company decisions depending on the impact of the e-waste disposal directive, decision-making on environmental design and the recovery process. They prove that the cost of the finished product plays a key role in deciding on the recovery or other ways of disposing of a product; therefore, it is necessary to develop a decision support model for the recovery, recycling or disposal of electronic products and waste.

However, along with the inclusion of standard costs of the design and manufacture of products, as well as the costs of the product management at the end of its life cycle, scientists do not take into account the damage from the negative environmental impact that occurs when choosing a non-priority method of handling products and waste (disposal at the landfill). Such damage can be included into the model as the economic losses of the company from the burial of the product and expressed as a percentage of GDP, but the assessment of this indicator is very difficult, moreover, this will not materially stimulate the manufacturer to restore and recycle products, therefore it is more logical to include into the model the indicator directly affecting the cost of production and reflecting the environmental impact. Such an indicator is the rate of environmental tax paid by the manufacturer in case of refusal to landfilled of the product.

\section{Research Methodology}


Choosing a way to dispose products at the end of the life cycle within the LCA methodology is an important issue to be considered throughout the value chain. Our methodology takes into account a closed life cycle from the moment of product design to the choice of disposal method. To date, there are no onesize-fits-all solutions for end-of-use product management. At the same time, a strategy for sustainable development and a circular economy requires an integrated approach that takes into account the social, environmental and economic consequences when choosing a disposal method. The research was carried out in three stages (Figure 1).

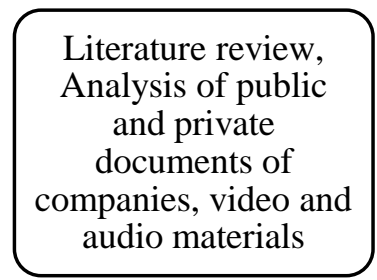

Literature review, and private documents of audio materials
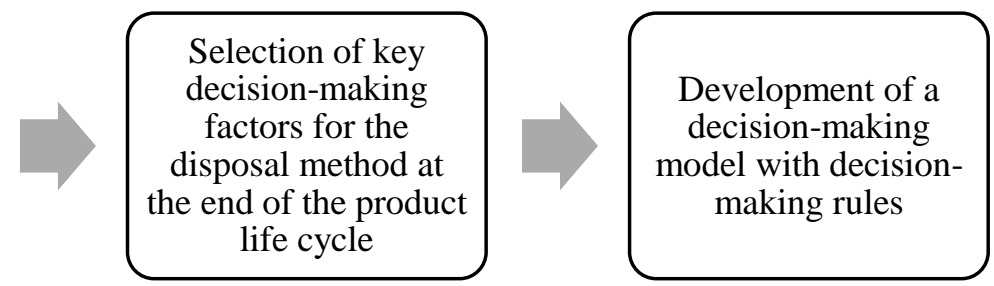

Fig. 1. Research stages

Considering the objectives of this study, a qualitative analysis of three types of data was carried out: public and internal company reports, research of the Google Scholar databases, Science Direct, Web of Science, audio and video materials. The keywords were "Closed Product Life Cycle", "Decision Making at the End of the Life Cycle", "Circular Economy", "Environmentally Effective Disposal". The data exploration identified the key decision factors for disposal at the end of the product life cycle in the context of a circular economy. The most significant factors are included into the decision-making model.

The developed decision-making model helps to select a scenario of an environmentally efficient disposal method: remanufacturing or recycling, in comparison with a typical landfill scenario. The LCA methodology assists in the choice of disposal method in terms of environmental impact and costs. At the same time, remanufacturing within the framework of the concept of a circular economy is the highest priority waste management method in comparison with recycling according to the methodology of the 9R Framework. All this made it possible to prioritize scenarios for choosing a disposal method at the micro level within the framework of extended producer responsibility.

\section{Results}

\subsection{Closed product life cycle}

Each product goes through three main stages of the life cycle in a simplified way: production, exploitation, end of the life cycle. At the same time, each stage, depending on the company's strategy, has different effects on the environment, relations with counterparties, and the company's final financial results. Figure 2 presents a closed product life cycle according to the principles of circular economy. With a closed life cycle at the end of use, the product is reused, remanufactured or recycled instead of disposal. 


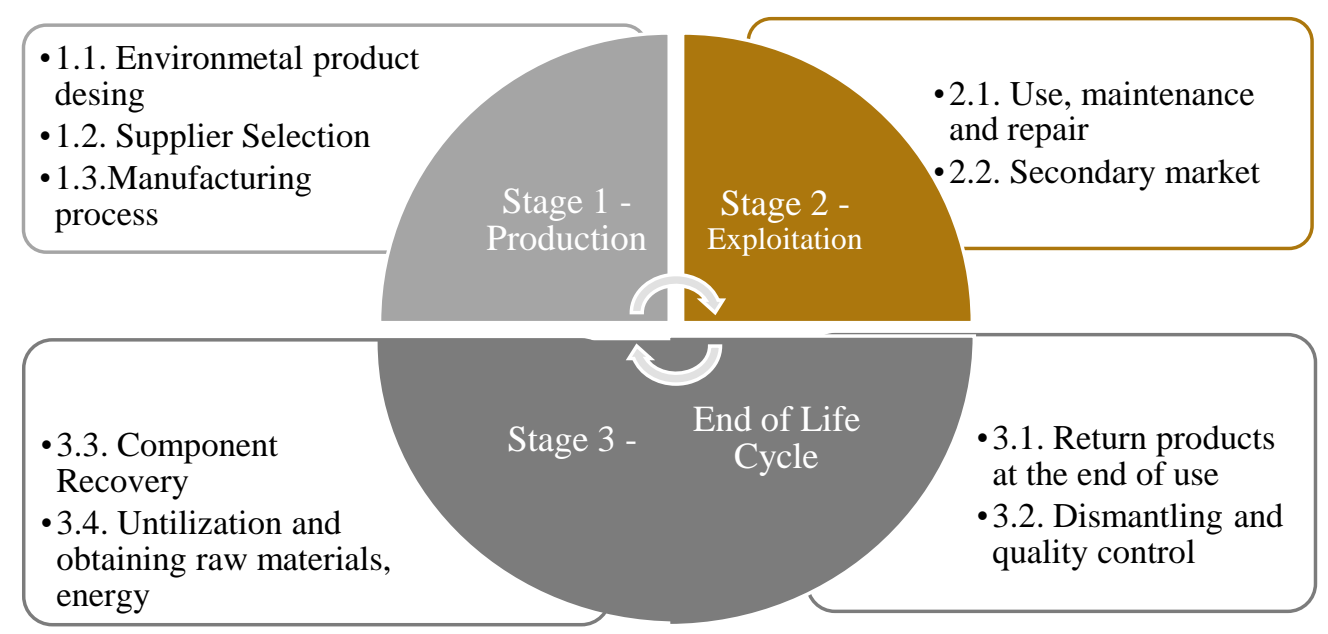

Figure 2. Closed product life cycle (Compiled by the authors)

The closed product life cycle implies a transition to new principles of circular production, which combines the tools of lean and green production, quality management and corporate social responsibility (Zhang, Badurdeen, Rouch \& Jawahir, 2013). So, the principles of circular production include: the environmental design of the product for its recovery and recycling, the use of eco-packaging for reuse, warehouse management with lean production and on-time delivery, the acquisition of fully recyclable or biodegradable materials, the implementation of environmental management and environmental audits, as well as the principles of non-waste and energy-efficient production.

Stage 1. Environmental design and production. Products are designed, certified and labeled so that in the future they can be dismantled with minimal manual labor for remanufacturing or recycling. The production of elements and components includes the selection of materials that are fully recyclable or biodegradable. In addition, each product must have a long-life cycle with the possibility of reuse and recovery. Big data and high-performance computing, suppliers search automation and digital twins provide a wide range of opportunities for eco-design development. The consumption of primary materials is minimized with the help of $3 \mathrm{D}$ printing, which allows not only to personalize products, but also to recycle $3 \mathrm{D}$ waste and convert it back into usable resources.

Stage 2. Thanks to digital technologies, new consumption models are actively developing. For example, the offer of services and goods in the temporary use as an alternative to acquisition of goods. Mass customization prevails over mass standardization, and continuous product development according to customer requirements is carried out using feedback and predictive analytics systems. Sharing and exchange platforms help to extend the product life cycle. In the process of use, products are controlled by manufacturers, and when they are exhausted, broken or outdated, they are effectively landfilled in the most environmentally friendly way. The use of automation technologies and predictive analytics at this stage is extremely important.

Stage 3. Effective collection and sorting of waste and used products are implemented using the Internet of things, feedback platforms and big data analytics. Monitoring the location and quality of the product, as well as identifying the persons responsible for disposal, is difficult to imagine without the use of digital technologies that optimize the return process for further recovery or recycling, which provides an individual approach to waste reuse, optimized transport routes and a detailed analysis of data on waste.

Stage 4. At the end of the product life cycle and after its return, the manufacturer must decide on the type of disposal, as well as the degree of product dismantling: restoration of components after complete 
dismantling of the product to the state "as new" (remanufacturing); re-processing of components after complete or partial dismantling of the product into new materials; burning waste for fuel; sending to the landfill for burial. Big data analytics is used to select one or another disposal method.

Thanks to digital technologies, it is possible to create an effective system for managing the closed life cycle of a product, which is the basis for the formation of a digital economy with a closed cycle. The author refers to the digital economy of a closed cycle as an economy in which direct value chains are optimally modeled and implemented for the purpose of restoring, reusing, optimizing and saving resources using digital technologies and innovative business models to simultaneously achieve non-waste production and consumption, sustainable economic growth, socio-economic and environmental efficiency.

\subsection{Decision making model for disposal method at the end of the product life cycle}

At the end of the life cycle, different methods of product management are possible, which depend on the introduction of recycling standards and environmental charges, the tightening of legislation in the field of extended manufacturer responsibility, the development of circular business models. Whereas earlier the disposal of products prevailed as the most profitable form of management of used products, today various methods of disposal of products and waste are used from recovery and recycling to composting and incineration with energy recovery. So, in developed countries, remanufacturing technologies are actively used to restore individual elements to the "as new" state. Remanufacturing is the highest priority form of endof-life product management in the context of a circular economy. At the end of use, the product goes through such stages as return to the manufacturer or the recycling center, dismantling and quality control, making a decision on the method of remanufacturing, recycling, reuse, and the process end of life cycle.

Choosing a product management strategy at the end of the life cycle, a decision-making model has been developed. The model will help to determine the choice of the most rational disposal strategy from an economic and environmental point of view, including when enterprises implement regulatory requirements from the state in the field of environmental legislation.

\section{Limitations:}

1. The model does not take into account the initial investment in the formation of closed supply chains and return logistics infrastructure for environmentally efficient product lifecycle management.

2. The model does not take into account the product return strategy and the costs associated with a particular strategy.

3. The weight of the material resulting from the recycling of the product does not change and does not differ from the weight of the product.

4. All products at the end of life cycle are subject to recycling, remanufacturing or disposal; there is no return flow from the manufacturer to the customer/supplier due to the lack of the possibility of disposal.

5. Disposal rates and environmental tax rates are set based on legislation and are subject to change.

6. The manufacturer can independently landfilled, recycle or remanufacture of the product or transfer this function to a third-party organization for an additional fee. If the product or its parts cannot be remanufactured, they are recycled into new materials.

7. The model does not take into account the restrictions on the manufacturer's capacities that are necessary for the landfill, recycle or remanufacture of products; it is assumed that all return flows can landfilled, recycled or remanufactured. 
Rule of decision 1. If the manufacturer makes a choice between recycle and landfill of the product, he must evaluate the costs associated with dismantling and recycling, as well as the added value of the recycled materials with the rate of environmental tax. If the rate of the environmental fee is lower than the cost of disposal, then the manufacturer will strive to landfill the products.

$$
C_{l, n} \times h_{n} \times\left(s_{n}-\frac{s_{n}}{T_{n}}\right)+V_{n} \times h_{n} \times \frac{s_{n}}{T_{n}}>s_{n} \times\left(P_{n}-C_{m}\right)
$$

Where:

- $\mathrm{C}_{\mathrm{l}, \mathrm{n}}-$ the cost of landfill of the product $\mathrm{n}$ (monetary units / $\mathrm{kg}$ )

- $\mathrm{s}_{\mathrm{n}}-$ number of returned products $\mathrm{n}(\mathrm{pcs})$

- $\mathrm{h}_{\mathrm{n}}$ - product weight $\mathrm{n}(\mathrm{kg}$.)

- $\mathrm{T}_{\mathrm{n}}-$ tax rate for landfill of product $\mathrm{n}(\mathrm{kg}$.)

- $\mathrm{V}_{\mathrm{n}}$ - environmental tax, which the manufacturer must pay in case of refusal of disposal and selection of the landfill of product $\mathrm{n}$ (units).

- $\mathrm{P}_{\mathrm{n}}-$ the price of the recovered product $\mathrm{n}$ (monetary units/pcs.)

- $\mathrm{C}_{\mathrm{rn}}-$ costs for remanufacturing (restoration) of the product $\mathrm{n}$ (monetary units/pcs.)

The costs of product remanufacturing $\mathrm{n}(\mathrm{Crn})$ consist of the sum of the costs of the initial acceptance and inspection of the product, transportation costs, the cost of dismantling the product, the cost of remanufacturing the product, and the cost of testing the product.

In this case, instead of the remanufacturing procedure, recycling can be used. So, instead of the price of the recovered product $P_{n}$, it is necessary to include the price of the recycled materials Pnm into the formula, and the cost of processing $\mathrm{C}_{\mathrm{dn}}$ instead of the costs of remanufacturing. When the manufacturer focuses on remanufacturing, profit (П) will equal (2):

$$
\Pi=\mathrm{zr} \times\left(\mathrm{P}_{\mathrm{n}}-\mathrm{C}_{\mathrm{r}, \mathrm{n}}\right)+\mathrm{zrd} \times\left(\mathrm{P}_{\mathrm{k}}-\mathrm{C}_{\mathrm{r}, \mathrm{k}}\right)+\mathrm{zdr} \times\left(\mathrm{P}_{\mathrm{n}, \mathrm{k}, \mathrm{m}}-\mathrm{C}_{\mathrm{d}, \mathrm{k}}\right)+\mathrm{zd} \times\left(\mathrm{P}_{\mathrm{n}, \mathrm{m}}-\mathrm{C}_{\mathrm{d}, \mathrm{n}}\right)
$$

Remanufacturing is appropriate in the case of (5), (6):

Where:

$$
\begin{gathered}
\operatorname{zr} \times\left(\mathrm{P}_{\mathrm{n}}-\mathrm{C}_{\mathrm{r}, \mathrm{n}}\right)>\operatorname{zd} \times\left(\mathrm{P}_{\mathrm{n}, \mathrm{m}}-\mathrm{C}_{\mathrm{d}, \mathrm{n}}\right) \\
\text { or } \\
\operatorname{zrd} \times\left(\mathrm{P}_{\mathrm{k}}-\mathrm{C}_{\mathrm{r}, \mathrm{k}}\right)>\operatorname{zdr} \times\left(\mathrm{P}_{\mathrm{n}, \mathrm{k}, \mathrm{m}}-\mathrm{C}_{\mathrm{d}, \mathrm{k}}\right)
\end{gathered}
$$

- $\mathrm{P}_{\mathrm{n}}$ - the price of the recovered product $\mathrm{n}$ (monetary unit / pcs.)

- $\mathrm{P}_{\mathrm{k}}$ - the price of the recovered component $\mathrm{k}$ (monetary unit / pcs.)

- $\mathrm{P}_{\mathrm{n}, \mathrm{k}, \mathrm{m}}$ - the price of the material $\mathrm{m}$ obtained by the complete dismantling of the product $\mathrm{n}$ and the recycling of components $\mathrm{k}$ (monetary unit / $\mathrm{kg}$ )

- $\mathrm{P}_{\mathrm{n}, \mathrm{m}}$ - the price of the material $\mathrm{m}$ obtained by partial dismantling and remanufacturing of the product $\mathrm{n}$ (monetary unit / kg)

- $\mathrm{C}_{\mathrm{d}, \mathrm{n}}-$ the cost of recycling of the product $\mathrm{n}$ with partial dismantling (monetary unit $/ \mathrm{kg}$ )

- $\mathrm{C}_{\mathrm{d}, \mathrm{k}}$ - the cost of recycling of the component $\mathrm{k}$ with the complete dismantling of the product $\mathrm{n}$ (monetary unit / kg)

- $\mathrm{C}_{\mathrm{r}, \mathrm{n}}-$ cost of remanufacturing (recovery) of the product $\mathrm{n}$ (monetary unit / pcs.) 
- $\mathrm{C}_{\mathrm{r}, \mathrm{k}}$ - the cost of remanufacturing (recovery) of component $\mathrm{k}$ in the product $\mathrm{n}$ (monetary units / unit)

Decision rule 3. Products that are not remanufacture due to technology or damage must be recycled. The manufacturer decides on the recycling of a partial or complete dismantling. When completely dismantled, cleaner fractions are obtained. The product is completely dismantled if the cost of dismantling and recycling is less than the added value of the materials obtained by complete dismantling, compared to the added value of the materials obtained by partial dismantling.

The decision to recycle the product with complete or partial dismantling must be made in accordance with (5):

$$
s_{n} \times\left(\frac{h_{n, m}}{h_{n}} \times P_{n, m}-C_{d, n}\right)>s_{n} \times K_{n, k} \times\left(\frac{h_{n, k, m}}{h_{n, k}} \times P_{n, k, m}-C_{d, k}\right)
$$

Where:

- $\mathrm{s}_{\mathrm{n}}-$ number of returned products $\mathrm{n}(\mathrm{pcs})$

- $\mathrm{h}_{\mathrm{n}, \mathrm{m}}$ - weight of material $\mathrm{m}$ obtained by partial dismantling and recycling of the product $\mathrm{n}(\mathrm{kg}$.)

- $\mathrm{h}_{\mathrm{n}}$ - product weight $\mathrm{n}(\mathrm{kg}$.)

- $\mathrm{h}_{\mathrm{n}, \mathrm{k}, \mathrm{m}}$ - the weight of material $\mathrm{m}$ obtained by the complete dismantling of the product $\mathrm{n}$ and the recycling of components $\mathrm{k}(\mathrm{kg}$.)

- $\mathrm{h}_{\mathrm{n}, \mathrm{k}}$ - the number of components $\mathrm{k}$ in the product $\mathrm{n}$ (pcs)

- $\mathrm{P}_{\mathrm{n}, \mathrm{k}, \mathrm{m}}$ - the price of the material $\mathrm{m}$ obtained by the complete dismantling of the product $\mathrm{n}$ and the recycling of components $\mathrm{k}$ (monetary unit $/ \mathrm{kg}$ )

- $\mathrm{P}_{\mathrm{n}, \mathrm{m}}$ - the price of the material $\mathrm{m}$ obtained by partial dismantling and recycling of the product $\mathrm{n}$ (monetary unit / kg)

- $\mathrm{C}_{\mathrm{d}, \mathrm{n}}-$ the cost of recycling the product $\mathrm{n}$ with partial dismantling (monetary unit $/ \mathrm{kg}$ )

- $\mathrm{C}_{\mathrm{d}, \mathrm{k}}$ - the cost of recycling the component $\mathrm{k}$ with the complete dismantling of the product $\mathrm{n}$ (monetary unit / kg)

Taking into account market changes, as well as increasing requirements by the State related to toughening environmental laws, implementation of disposal standards and environmental charges, manufacturers must choose between paying fees and various methods of management at the end of use product. So, the rules for deciding on the method of landfill of the product at the end of life cycle are based on the costs associated with dismantling and recovery / recycling, as well as the benefit of the recovered products / recycled materials when comparing the sums of the relevant parameters with the environmental tax rate. If the environmental tax rate is lower than the cost of landfill, then the manufacturer will opt for the burial of products, which is impractical from the point of view of resource and energy conservation, and will signal the state to increase environmental taxes to build an ecologically and cost-effective waste and obsolete products system management in the country.

\subsection{Analysis of the development of closed supply chains trends}

The essence of supply chain management at the end of the product life cycle is to coordinate the activities of participants with the aim of organizing logistics processes, as well as reducing the cost, time and risks of passing products along the supply chain for the purpose of further landfill in one way or another. Thus, for the development of a circular economy, it is necessary to form closed supply chains, which are understood as 
supply chains that increase added value throughout the entire life cycle of a product with dynamic recovery within relatively long time intervals of values of various types and volumes (Guide, 2009). At best, the formation of closed supply chains implies zero waste, and the development of reverse logistics in all industries makes possible the formation of a circular economy as a whole. Meanwhile, the circular economy goes beyond recycling at the end of the product life cycle and allows for technological and social innovation to be generated throughout the value chain, with the goal of sustainable product design and waste prevention. Before the digitalization processes, the coordination of participants was carried out by the companies themselves and intermediary companies, as a rule, using information systems (ERP, CRM, SRM, WMS and others), which complicated the process of formation and development of a circular economy both from the technology side and from the operating costs side.

The main trends in the formation and development of closed supply chains under the influence of digital technologies are as follows:

- Optimization of closing chain processes is supported by digital technologies such as big data analytics and high-performance computing, supplier search automation and digital twins, which provide a wide range of opportunities for the development of closed supply chains. With the introduction of digital technologies and databases on products and materials, suppliers and technologies, companies are able to optimize not only the direct supply chain, but also effectively manage the return flows through access to transparent and secure data.

- The economic feasibility of managing return flows is achieved through technologies such as the Internet of Things, which is a network of sensors that collect data from various devices, analytics of which help predict equipment breakdowns and replace worn parts in advance, carry out maintenance and repairs; it is also possible to monitor the deviation of the production process from the established standards, which allows to quickly track the problem to avoid rejects and waste. Robotic technologies, replacing manual labor, optimizes the production process in terms of accuracy and minimizes the cost of operations. 3D printing allows not only to personalize products and reduce consumption, but also to recycle 3D waste, turning it into usable 3D materials. All this increases labor productivity, automates business processes, saves on downtime, repairs, rejects, information obtained using big data analytics; it is used when making decisions about manipulating a specific product at different stages of its life cycle, significantly reducing operating costs and increasing the economic feasibility of managing closed supply chains in general.

- Coordination of subjects and objects of the supply chain by means of the Internet of Things, feedback platform and big data analytics. All these technologies are used to monitor the location, quality and ownership of products, to determine the entities responsible for disposal, as well as to collect, store and process information on the quality and quantity of products, their composition and disposal options. The expenses on tracing products and materials, and feedback for product return using the Internet of Things, are significantly reduced and make it possible to organize and manage the return flows of products and wastes.

- Environmental efficiency is achieved through sustainable product design, production and consumption processes. Ecological design is aimed at zero waste production and consumption, resource intensity reduction and increase of the efficiency of raw materials and energy resources throughout the value chain. Companies need transparent and secure data for ecological design with an emphasis on circular design, which can be achieved by blockchain, establishment of databases on products and materials, suppliers and technologies. Ecological design aims to develop products that are durable, easy to replace and recyclable, because the development of a product-as-a-service business model reduces the demand for physical assets produced by companies, resulting in savings in resource consumption and less waste. 
- Individualization and customer focus is supported by IoT sensors, when products begin to have feedback with the owner, including without user participation, in order to generate predictive analytics, personalization, and improve quality and design. Sensors track the product, collect and analyze data on its use in order to increase sustainability. Thus, the collection and analytics of data allows to provide an up-to-date extended post-warranty service, to carry out timely delivery of certified spare parts and components to increase the duration of product use, as well as to establish an effective system for returning products from user to owner for the purpose of environmentally efficient disposal or reuse. Digital platforms promote product sharing and optimal consumption as they help to establish relationships and improve communication between users and the manufacturer, to provide information on correct sustainable consumption for a long product life, to optimize the repair process through the use of related products and predictive maintenance, proactive automatic notifications for diagnostic maintenance.

Today, enterprises of all sectors and industrial complexes, from the healthcare sector to the financial sector and large-scale production, are subject to digital transformation. According to forecasts, within 10 years, about $50 \%$ of the largest revenue companies from the Fortune Global 500 will be replaced by innovative digital enterprises (Anthony, Viguerie \& Waldeck, 2016). Therefore, savings on the introduction of digital technologies, including for the formation and development of closed supply chains in order to disseminate the principles of a circular economy, today may result in a decrease in the company's competitiveness in the future. Innovative digital technologies have the potential to change consumer expectations, operational and communication processes, forms and characteristics of supply chains, and are used to transform any economic system. Changes will occur due to broader and deeper automation of processes, the use of more detailed analytics, as well as the creation of digital platforms and circular supply systems instead of linear models. All this will promote the reduction of the cost of the collection, sorting, dismantling, recovery, reuse and recycling of used products to achieve economic, environmental and social efficiency.

\section{Discussion}

At the end of the use of the company's products, following the principles of the circular economy, they decide on the method of disposal of the product or its reuse, based not only on the possibilities of using a particular operation, but also on the economic feasibility of the whole process. In this connection, the study proposed a decision-making model for choosing the method of disposal of used products. The proposed decision-making model makes it possible to make a choice of the disposal method based not only on costs and revenues, but also on the impact on the environment. The proposed approach has the integrity of criteria in the context of circular economy and includes not only economic factors of decision-making, but also environmental aspects.

The document discusses important aspects of the formation of closed supply chains, taking into account digital technologies, which form the basis of the transition to a circular economy. It is concluded that the main trends in the digitalization of supply chains will help to optimize the cost of managing the end of the product life cycle, and the main orientation in the choice of the disposal method will contribute to achieving environmental and social efficiency.

The application of the agent-based approach will allow identifying the characteristics of individual producers and consumers for modeling their behavior and activities, developing closed supply chains to improve environmental and economic efficiency in order to establish environmental fee rates and recycling standards, discounts on the return flow of products and environmentally effective end-of-life management of the product. 


\section{Conclusion}

The results of the study can be used to develop programs for the transition to a circular economy at the micro level, to build an effective waste management system, and to create an institutional and regulatory environment. All this will increase the environmental and economic efficiency of individual companies, allow them to save resources within a closed value chain, reduce waste, create new business lines, create additional jobs, and achieve the goals of sustainable development in general. Thus, the development of the digital circular economy, and in particular the closed product life cycle model, is an important task for researchers and scientists, government officials and businesses.

\section{Acknowledgements}

The article was carried out within the grant of the President of the Russian Federation for state support of young Russian scientists - candidates of science, project number MK-1278.2020.6.

\section{References}

Alamerew, Y. A., \& Brissaud, D. (2019). Circular economy assessment tool for end of life product recovery strategies. Journal of Remanufacturing, 9(3), 169-185.https://doi.org/10.1007/s13243-018-0064-8

Allesch, A., \& Brunner, P. H. (2014). Assessment methods for solid waste management: A literature review. Waste Management \& Research, 32(6), 461-473.https://doi.org/10.1177/0734242X14535653

Alter, S. 1980. Decision Support Systems: Current Practice and Continuing Challenge. Reading, MA: Addison-Wesley, 1980. Google Scholar [Date: 02.07.2020]

Anthony, S., Viguerie, P. \& Waldeck, A. (2016). Corporate Longevity: Turbulence Ahead for Large Organizations. Innosight executive briefing. https://www.innosight.com/wp-content/uploads/2016/08/Corporate-Longevity-2016Final.pdf [Date: 02.07.2020]

Antikainen, M., Uusitalo, T., \& Kivikytö-Reponen, P. (2018). Digitalisation as an enabler of circular economy. Procedia CIRP, 73, 45-49. https://doi.org/10.1016/j.procir.2018.04.027

Arenkov, I., Tsenzharik, M., \& Vetrova, M. (2019, September). Digital technologies in supply chain management. In International Conference on Digital Technologies in Logistics and Infrastructure (ICDTLI 2019) (pp. 448-453). Atlantis Press. https://doi.org/10.2991/icdtli-19.2019.78

Vásquez, D. Z., Ferreira, G., Usón, A. A., \& Bribián, I. Z. (2012). Environmental implications of the valorisation of the residual fraction refused by MBT plants. Chemical Engineering Transactions, 29, 1027-1032. https://doi.org/10.3303/CET1229172

Cremiato, R., Mastellone, M. L., Tagliaferri, C., Zaccariello, L., \& Lettieri, P. (2018). Environmental impact of municipal solid waste management using Life Cycle Assessment: The effect of anaerobic digestion, materials recovery and secondary fuels production. Renewable Energy, 124, 180-188.https://doi.org/10.1016/j.renene.2017.06.033.

Dijkman, R. M., Sprenkels, B., Peeters, T. J. G., \& Janssen, A. 2015. Business models for the internet of things. International Journal of Information Management 35(6): 672-678. https://doi.org/10.1016/j.ijinfomgt.2015.07.008

Ferronato, N., Rada, E. C., Portillo, M. A. G., Cioca, L. I., Ragazzi, M., \& Torretta, V. (2019). Introduction of the circular economy within developing regions: A comparative analysis of advantages and opportunities for waste valorization. Journal of environmental management, 230, 366-378.https://doi.org/10.1016/j.jenvman.2018.09.095.

Frey, C. B., \& Osborne, M. A. (2017). The future of employment: How susceptible are jobs to computerisation? Technological forecasting and social change, 114, 254-280. https://doi.org/10.1016/j.techfore.2016.08.019

Ghisellini, P., Ji, X., Liu, G., \& Ulgiati, S. (2018). Evaluating the transition towards cleaner production in the construction and demolition sector of China: A review. Journal of cleaner production, 195, 418-434. https://doi.org/10.1016/J.JCLEPRO.2018.05.084

R Jr, V. D., \& Van Wassenhove, L. N. (2009). The Evolution of Closed-Loop Supply Chain Research. Operations research, (1), 10-19. https://doi.org/10.1287/opre.1080.0628 
Gungor, A., \& Gupta, S. M. (1999). Issues in environmentally conscious manufacturing and product recovery: a survey. Computers \& Industrial Engineering, 36(4), 811-853. https://doi.org/10.1016/S0360-8352(99)00167-9

Jawahir, I. S., \& Bradley, R. (2016). Technological elements of circular economy and the principles of 6R-based closed-loop material flow in sustainable manufacturing. Procedia Cirp, 40, $103-108$. https://doi.org/10.1016/j.procir.2016.01.067

John Deere. (2019). John Deere Hosts Annual Reman Day. Cites Environmental Benefits URL: https://www.forestrytrader.com/blog/forestry-equipment-news/2019/04/john-deere-hosts-annual-reman-day-citesenvironmental-benefits [Date: 02.07.2020]

Kagermann, H., Lukas \& W. Wahlster, W. (2011). Industrie4.0: With the Internet of Things on the way to the 4th industrial revolution. VDI news 13. URL: http://www.wolfgang-wahlster.de/wordpress/wpcontent/uploads/Industrie_4_0_Mit_dem_Internet_der_Dinge_auf_dem_Weg_zur_vierten_industriellen_Revolution_2. pdf [Date: 02.07.2020]

Mahmoudzadeh, M., Mansour, S., \& Karimi, B. (2013). To develop a third-party reverse logistics network for end-oflife vehicles in Iran. Resources, Conservation and Recycling, 78, 1-14. https://doi.org/10.1016/j.resconrec.2013.06.006

Kirchherr, J., Reike, D., \& Hekkert, M. (2017). Conceptualizing the circular economy: An analysis of 114 definitions. Resources, conservation and recycling, 127, 221-232. https://doi.org/10.1016/j.resconrec.2017.09.005

Mohan, T. K., \& Amit, R. K. (2020). Dismantlers' dilemma in end-of-life vehicle recycling markets: a system dynamics model. Annals of Operations Research, 290(1), 591-619. https://doi.org/10.1007/s10479-018-2930-z

Kristoffersen, E., Blomsma, F., Mikalef, P., \& Li, J. (2020). The smart circular economy: A digital-enabled circular strategies framework for manufacturing companies. Journal of Business Research, 120, 241-261. https://doi.org/10.1016/j.jbusres.2020.07.044

Kumar, V., Shirodkar, P. S., Camelio, J. A., \& Sutherland, J. W. (2007). Value flow characterization during product lifecycle to assist in recovery decisions. International Journal of Production Research, 45(18-19), 4555-4572. https://doi.org/10.1080/00207540701474633

Lewandowski, M. (2016). Designing the business models for circular economy-Towards the conceptual framework. Sustainability, 8(1), 43.https://doi.org/10.3390/su8010043

Milutinović, B., Stefanović, G., Đekić, P. S., Mijailović, I., \& Tomić, M. (2017). Environmental assessment of waste management scenarios with energy recovery using life cycle assessment and multi-criteria analysis. Energy, 137, 917926.https://10.1016/j.energy.2017.02.167.

Morrissey, A. J., \& Browne, J. (2004). Waste management models and their application to sustainable waste management. Waste management, 24(3), 297-308. https://doi.org/10.1016/j.wasman.2003.09.005

Negroponte, N. (1995). Being Digital. Knopf. Paperback edition, Vintage Books, ISBN 0-679-76290-6 URL: http://governance40.com/wp-content/uploads/2018/12/Nicholas-Negroponte-Being-Digital-Vintage-1996.pdf [Date: 02.07.2020]

Ngan, S. L., How, B. S., Teng, S. Y., Promentilla, M. A. B., Yatim, P., Er, A. C., \& Lam, H. L. (2019). Prioritization of sustainability indicators for promoting the circular economy: The case of developing countries. Renewable and sustainable energy reviews, 111, 314-331. https://doi.org/10.1016/j.rser.2019.05.001

Pakhomova, N. V., Richter, K. K., \& Vetrova, M. A. (2017). Transition to circular economy and closedloop supply chains as driver of sustainable development. https://doi.org/10.21638/11701/spbu05.2017.203

Pakhomova, N., Richter, K. \& Vetrova, M. (2017). Circular economy as challenge to the fourth industrial revolution. Innovations 7 URL: https://maginnov.ru/en/magazine/archive/2017/innovations-n7-2017/circular-economy-aschallenge-to-the-fourth-industrial-revolution [Date: 02.07.2020]

Ruiz-Peñalver, S. M., Rodríguez, M., \& Camacho, J. A. (2019). A waste generation input output analysis: The case of Spain. Journal of Cleaner Production, 210, 1475-1482.https://10.1016/j.jclepro.2018.11.145.

Simic, V., \& Dimitrijevic, B. (2012). Production planning for vehicle recycling factories in the EU legislative and global business environments. Resources, Conservation and Recycling, 60, 78-88. https://doi.org/10.1016/j.resconrec.2011.11.012

Stewart, D. \& Ijomah, W. (2011). Moving forward in reverse: a review into strategic decision making in reverse logistics. In: International Conference on Remanufacturing - ICoR, 2011-07-27 - 2011-07-29, University of Strathclyde URL: 
https://strathprints.strath.ac.uk/57749/1/Stewart_Ijomah_2011_Moving_forward_in_reverse_a_review_into_strategic.p df [Date: 02.07.2020]

Tsai, F. M., Bui, T. D., Tseng, M. L., Lim, M. K., \& Hu, J. (2020). Municipal solid waste management in a circular economy: A data-driven bibliometric analysis. Journal of Cleaner Production, 275, 124132.https://doi.org/10.1016/j.jclepro.2020.124132

Yang, S. S., Ngiam, H. Y., Ong, S. K., \& Nee, A. Y. C. (2015). The impact of automotive product remanufacturing on environmental performance. Procedia Cirp, 29, 774-779.https://doi.org/10.1016/j.procir.2015.01.017

Whitwam, R. (2017). Apple unveils 29-armed robot designed to disassemble old iPhones URL: https://www.extremetech.com/mobile/225337-apple-unveils-29-armed-robot-designed-to-disassemble-old-iphones [Date: 02.07.2020]

Wolfram, G., Gampl, B., \& Gabriel, P. (Eds.). (2008). The RFID roadmap: The next steps for Europe. Springer Science \& Business Media. https://doi.org/10.1007/978-3-540-71019-6

Zaccariello, L., Cremiato, R., \& Mastellone, M. L. (2015). Evaluation of municipal solid waste management performance by material flow analysis: Theoretical approach and case study. Waste Management \& Research, 33(10), 871-885. https://doi.org/10.1177/0734242X15595284.

Zhang, X., Badurdeen, F., Rouch, K., \& Jawahir, I. S. (2013). On improving the product sustainability of metallic automotive components by using the total life-cycle approach and the 6R methodology. 10.14279/depositonce-3753. http://dx.doi.org/10.14279/depositonce-4714

Zuidwijk, R., \& Krikke, H. (2008). Strategic response to EEE returns: Product eco-design or new recovery processes? European Journal of Operational Research, 191(3), 1206-1222.https://doi.org/10.1016/j.ejor.2007.08.004 